\title{
Inverted deposition and high-velocity spinning to develop buried planar chalcogenide glass waveguides for highly nonlinear integrated optics
}

\author{
A. K. Mairaj, ${ }^{\text {a) }}$ R. J. Curry, and D. W. Hewak \\ Optoelectronics Research Centre, University of Southampton, Southampton, S017 1BJ, United Kingdom
}

(Received 3 September 2004; accepted 30 November 2004; published online 23 February 2005)

\begin{abstract}
We report on buried planar waveguides in a highly nonlinear infrared transmitting chalcogenide glass, fabricated using a combination of inverted deposition of the molten glass phase and high-velocity spinning. Films of gallium lanthanum sulphide (Ga:La:S) glass were deposited onto an expansion coefficient matched Ga:La:S cladding substrate. These amorphous films, with an optimized composition designed to be resistant against crystallization, were observed to have an excellent interface quality and uniformity. The designed planar chip had a buried core, $6 \mu \mathrm{m}$ thick in the vertical direction, in single-mode operation at $1.064 \mu \mathrm{m}$ and a measured propagation loss of $<0.2 \mathrm{~dB} \mathrm{~cm}^{-1}$. Through this technique waveguides from Ga:La:S glass, a highly versatile optical semiconductor material, can potentially be used in nonlinear applications as well as provide passive and active integrated optic functionality into the infrared beyond $5 \mu \mathrm{m}$. () 2005 American Institute of Physics. [DOI: 10.1063/1.1856686]
\end{abstract}

Highly nonlinear glass has the potential to address a wide range of technologies. However, the development of this glass technology in planar platforms currently lags a generation behind conventional glass (silica based) integrated optic research and development. A highly nonlinear IR and transmitting thin film/planar device can effectively operate in a variety of systems, e.g., optical switches and lasers, modulators, sensors, grating based devices, IR radiation conduits, antireflection coatings, data storage, and generation of supercontinuum. ${ }^{1-4}$ Some examples of highly nonlinear materials include As-S, As-Se, Ge-S, Ge-Se-Te, and $\mathrm{Ga}-\mathrm{La}-\mathrm{S}$. The increasing sophistication of the industries requiring optical thin films from unconventional materials calls for alternative fabrication methods to be matured, which is the subject of this letter. ${ }^{5}$

In the highly nonlinear and IR transmitting family of materials, in particular the chalcogenide glasses (ChGs), the synthesis of thin films have been reported. ${ }^{6-9}$ Chalcogenide glasses contain elements from group VI of the periodic table as glass-forming anions and are generally opaque in the visible, with the exception of some sulphide glasses, and exhibit transparency extending into the longer infrared wavelengths (5-15 $\mu \mathrm{m})$ as compared with conventional glasses. The high nonlinear refractive index, enhanced IR transmission coupled with reduced phonon energy, and the ability to exhibit localized photoinduced material changes (reversible or irreversible), suggest these glasses are indeed fascinating candidates for planar waveguide development. A noteworthy member of the $\mathrm{ChG}$ family is the gallium lanthanum sulphide (Ga:La:S) glass system, having an optical transparency between 0.5 and $10 \mu \mathrm{m}$, a high glass transition temperature $\left(T_{g}\right)$ of $580{ }^{\circ} \mathrm{C}$, high solubility of rare-earths, transition, and precious metals (e.g., silver and platinum) and controllable photosensitivity. ${ }^{10}$ In addition, it has been reported that $\mathrm{Ga}: \mathrm{La}: \mathrm{S}$ optical glass has the highest optical nonlinearity as compared with other glasses (200 times higher than conven-

\footnotetext{
${ }^{a)}$ Electronic mail: mkam@orc.soton.ac.uk
}

tional silica glass). ${ }^{11}$ This suggests single-mode operating $\mathrm{Ga}: \mathrm{La}: \mathrm{S}$ glass planar waveguides could potentially be beneficial in a variety of nonlinear applications, e.g., generation of supercontinuum to realize optical coherence tomography systems and ultrafast all-optical switching. Thin films of $\mathrm{Ga}: \mathrm{La}: \mathrm{S}$ glass have previously been deposited using pulsed laser deposition over a relatively small surface area $\left(1 \mathrm{~cm}^{2}\right)$. This was with limited success as multicomponent materials tend to preferentially separate (due to largely varying vapor pressures) and deposit in a stoichiometrically homogeneous manner. ${ }^{9}$ However, the fabrication of stoichiometrically homogeneous thin films, from a multicomponent fluoride glass system, has been reported utilizing an alternative technique. ${ }^{12}$ In our previous work, we have presented the technique of inverted deposition of the molten phase combined with high velocity spinning for the development of chalcogenide thin films. ${ }^{13}$ In this letter, we further this work through the demonstration of single-mode and low propagation loss buried planar waveguides in Ga:La:S ChG for highly nonlinear integrated optics.

The rheological analysis of a material moving in response to a specified speed and exposed to a certain force involves the understanding of shear stress and shear rate. Shear stress is used to quantify the magnitude of a force driving a flow process and shear rate quantifies the speed of any flow deformation. For a small section of a liquid where a force, $F$, is acting over an area, $A$, across the top surface, the ratio of force to area gives shear stress $(\tau)$ across the liquid and the response of the liquid to flow. A velocity gradient forms between the surfaces of the liquid and this is known as the shear rate $(D)$ with the viscosity $(\eta)$ defined as the ratio of the shear stress to the shear rate. Newtonian fluids exhibit a linear relationship between shear stress and shear rate, with viscosity independent of the applied shear conditions. In the case of a polymer film, deposition using spin coating accelerates the coating material (fluid) deposited in the center of a substrate. This complex process involves a balance between centrifugal forces, controlled by spin velocity, and viscous forces which are determined by fluid viscosity and the 
TABLE I. Selected thermal and optical properties of the studied Ga: La: S ChG compositions.

\begin{tabular}{|c|c|c|c|c|c|c|c|c|c|c|}
\hline \multirow[b]{2}{*}{ Glass } & \multirow[b]{2}{*}{ Type } & \multicolumn{3}{|c|}{ Molar composition $\%$} & \multicolumn{4}{|c|}{$\left({ }^{\circ} \mathrm{C}\right)$} & \multirow{2}{*}{$\frac{a\left({ }^{\circ} \mathrm{C}^{-1}\right)}{\left(\times 10^{-6}\right)}$} & \multirow{2}{*}{$\frac{n}{\text { at } 1 \mu \mathrm{m}}$} \\
\hline & & $\mathrm{Ga}_{2} \mathrm{~S}_{3}$ & $\mathrm{La}_{2} \mathrm{~S}_{3}$ & $\mathrm{La}_{2} \mathrm{O}_{3}$ & $T_{g}$ & $T_{x}$ & $T_{p}$ & $T_{p}-T_{x}$ & & \\
\hline $\mathrm{GLS}_{1}$ & Substrate & 72.5 & 21.5 & 6 & 572 & 703 & 755 & 52 & 10.0 & 2.3475 \\
\hline $\mathrm{GLS}_{2}$ & Core & 65.0 & 32.0 & 3 & 578 & 728 & 749 & 21 & 10.2 & 2.3901 \\
\hline $\mathrm{GLS}_{3}$ & Core & 70.0 & 24.0 & 6 & 586 & 730 & 761 & 31 & 9.9 & 2.3674 \\
\hline
\end{tabular}

change in viscosity with time. A higher material viscosity (dependent on temperature), low spin velocity, and a shorter spin time can lead toward thicker films. Furthermore, variation in any of these parameters will undoubtedly influence the uniformity and thickness of the coating. The inverted deposition technique utilized in this work is analogous to the conventional polymer spin coating albeit the deposited material is molten rather than solution. The flow of viscous liquids on a rotating disk has been solved where the thickness, $h$, of an initially uniform nonvolatile Newtonian liquid at time $t$, on a rotating disk ${ }^{14}$

$$
h=\frac{h_{0}}{\left[1+\left(4 h_{0}^{2} t \rho \omega^{2} / 3 \eta\right)^{1 / 2}\right]},
$$

where $h_{0}$ is the initial film thickness, $\rho$ is the liquid density, $\omega$ is the angular velocity, and $\eta$ is the solution viscosity. From Eq. (1), the theoretical thickness of a Ga:La:S glass film, with $\rho=4000 \mathrm{~kg} \mathrm{~m}^{-3}$ and $\eta=0.1 \mathrm{P}$ (Ga:La:S glass at $1150{ }^{\circ} \mathrm{C}$ ), can be obtained. For $h_{0}=1 \mathrm{~mm}$ and a spin velocity of $2000 \mathrm{rpm}\left(\omega=314 \mathrm{rad} \mathrm{s}^{-1}\right)$ for $10 \mathrm{~s}$, the theoretical film thickness achieved is $\sim 4.4 \mu \mathrm{m}$. Equation (1) does not account for increased viscosity with time, as would be the case, due to the rapid quench of a small volume of molten glass.

Fabrication of the Ga:La:S ChGs used in the experiments was carried out from prepared batches of powder precursors processed within our laboratories with a purity exceeding $99.999 \%$. These glass precursors were loaded into a vitreous carbon crucible while in a controlled nitrogen atmosphere. The precursors are nonvolatile at the glass melting temperature $\left(1150{ }^{\circ} \mathrm{C}\right.$ for up to $\left.24 \mathrm{~h}\right)$ and were heated in an open (argon purged) atmosphere, after which the melt was quenched and annealed. Glasses with a typical molar composition of $72.5 \mathrm{Ga}_{2} \mathrm{~S}_{3}: 21.5 \mathrm{La}_{2} \mathrm{~S}_{3}: 6 \mathrm{La}_{2} \mathrm{O}_{3}$ for the cladding substrates $(n=2.3475$ at $1 \mu \mathrm{m})$ and core glass compositions given in Table I were prepared. The thermal characteristics of the Ga:La:S glasses used in this work were then investigated with differential thermal (Perkin-Elmer DTA 7) and thermo-mechanical analyzers (Perkin-Elmer 7). This thermal equipment was calibrated prior to any measurements and background subtraction was performed with measurements having an error margin of $\pm 1.5^{\circ} \mathrm{C}$. The DTA allowed evaluation of characteristic thermal events, at $10{ }^{\circ} \mathrm{C} \mathrm{min}-1$, that require (endothermic) or release (exothermic) heat as a function of temperature. The DTA thermograms showed distinct events starting with glass transition $\left(T_{g}\right)$ where glass solid and liquid phases intersect, followed by the onset of $\left(T_{x}\right)$ and presentation of a crystallization peak $\left(T_{p}\right)$ (heating rate influences onset of all these events). To function effectively as an optical waveguide, it is crucial for the deposited film to be amorphous. Therefore, the separation of the peak and the onset of crystallization temperature $\left(T_{p}-T_{x}\right)$ is required to be suitably

broad $\left(>25^{\circ} \mathrm{C}\right)$. A narrow separation $\left(25^{\circ} \mathrm{C}\right)$ suggests a well- defined crystalline event which will have structural prevalence over any amorphous lattice configuration. However, careful optimization of glass network former, modifier, and stabilizer content can result in significant suppression of crystal phases and favor the formation of an amorphous structure within the quenched film. The thermal expansion coefficient, $\alpha$, of the studied glasses was assessed with a TMA having an operation load of $10 \mathrm{mN}$. Sample height deformation as a function of temperature, measured between 300 and $500{ }^{\circ} \mathrm{C}$ increased at $10^{\circ} \mathrm{C} \mathrm{min}^{-1}$, allowed derivation of $\alpha$. A table of the studied Ga:La:S glass compositions $\mathrm{GLS}_{1-3}$ is shown in Table I. As is prerequisite for the core glass, the substrate is also required to be suitably resistant against crystallization due to the nature of this particular thin film fabrication process. For $\mathrm{GLS}_{1}$ the $T_{p}-T_{x}$ figure was measured to be $52{ }^{\circ} \mathrm{C}$. Also the observed weak exothermic crystalline event $\left(T_{p}\right)$ suggests this composition was sufficiently resistant against crystallization and was selected as the substrate material. In the case of selecting a suitable core glass a higher lanthanum content is required, as compared with the cladding glass, as this leads to increased material polarizability as seen in $\mathrm{GLS}_{2}(n=2.3901$ at $1 \mu \mathrm{m})$ and $\operatorname{GLS}_{3}(n=2.3674$ at $1 \mu \mathrm{m})$. For $\mathrm{GLS}_{2}$ and $\mathrm{GLS}_{3}$, a value of 21 and $31{ }^{\circ} \mathrm{C}$ was measured, respectively, as the $T_{p}-T_{x}$ figure and their observed exothermic crystalline events $\left(T_{p}\right)$ were more prominent than $\mathrm{GLS}_{1}\left(\mathrm{GLS}_{2}\right.$ more so than $\left.\mathrm{GLS}_{3}\right)$. These thermal analysis results suggest $\mathrm{GLS}_{3}$ is more resistant against crystallization as compared with $\mathrm{GLS}_{2}$ and a superior composition for use in this thin film fabrication process. The thermal expansion coefficients for $\mathrm{GLS}_{1-3}$ glasses were measured to be within $\pm 0.15 \times 10^{-6}{ }^{\circ} \mathrm{C}^{-1}$ of each other. Disparate thermal expansion coefficients between the substrate and deposited film can result in structural damage during cooling to ambient conditions.

Each substrate shaped as a disk had a diameter and thickness of 29 by $2 \mathrm{~mm}$, respectively, and was optically polished on the top and bottom face. An optically flat polish on the material deposition surface is essential as this enhances interfacial uniformity between the deposited film and substrate. The fabrication of buried planar waveguides of $\mathrm{Ga}: \mathrm{La}: \mathrm{S}$ glass involved three primary stages as shown in Fig. 1. The first stage involves the deposition of the coating fluid (molten glass) onto the substrate surface which is held in place by a boron nitride vacuum chuck. A crucible con-

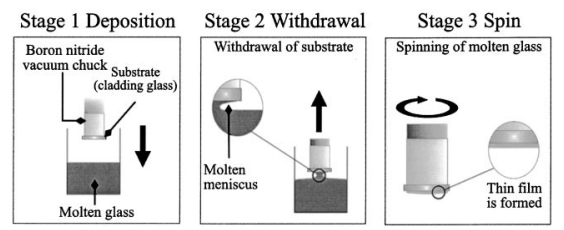

FIG. 1. The 3-step process of inverted deposition and high velocity spinning for developing buried planar chalcogenide glass waveguides (Ref. 14). 


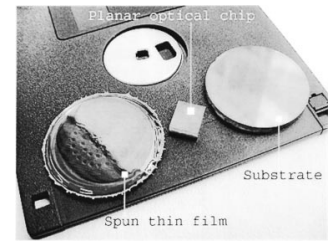

FIG. 2. (from left to right) A disk with a buried planar waveguide with spun core-clad films, planar optical chip, and clad glass substrate from the Ga:La:S glass system.

taining molten glass $\left(\sim 1250^{\circ} \mathrm{C}\right)$ makes slight contact with the substrate surface. The preheated $\mathrm{Ga}: \mathrm{La}: \mathrm{S}$ glass substrate $\left(\sim 540{ }^{\circ} \mathrm{C}\right)$ is dipped approximately $1 \mathrm{~mm}$ into the molten $\mathrm{Ga}: \mathrm{La}: \mathrm{S}$ glass. It is vital that the substrate surface is completely wet with molten glass during this stage. Normally a substantial excess of coating fluid is deposited in comparison with the final film thickness. During the second stage the substrate is withdrawn, within $200 \mathrm{~ms}$ after contact, from the molten glass surface but still positioned within the walls of the crucible. The excess molten deposited glass on the substrate surface forms a meniscus as it drips back into the crucible. Positioning the substrate as such is a precautionary stage as any molten glass expelled from the substrate surface during the third stage (spin cycle) is collected within the crucible. The third stage is typically characterized by the expulsion of deposited fluid from the substrate surface through a rotational motion. The substrate is accelerated to a preset angular velocity for a specified duration and when spinning at a constant rate, viscous forces dominate fluid thinning. The crucible is fully withdrawn from the substrate $2 \mathrm{~s}$ after the spin cycle has started. This reduces the effects of thermal radiation, emanating from the hot crucible and molten glass below, which can retard the quench of the deposited film. The deposited molten film thins out and cools until the viscosity is too high for further flow to occur. Following the third stage, the substrate and deposited amorphous film are annealed at $540{ }^{\circ} \mathrm{C}$ for $1 \mathrm{~h}$ and then slowly cooled, at $1{ }^{\circ} \mathrm{C} \mathrm{min}{ }^{-1}$, to an ambient temperature.

In Fig. 2, a disk with spun thin films fabricated using the aforementioned technique, a planar optical chip with a buried waveguide and a substrate from the Ga:La:S glass system is shown. The planar optical chip has been cut from a spun film disk and can be scaled in size to suit an application. The above-mentioned three-step process was used for the initial deposition of the 18- $\mu \mathrm{m}$-thick core layer [Fig. 3(a)] and was repeated for a second deposition of an overcladding layer (>40 $\mu \mathrm{m}$ thick) [Fig. 3(b)]. The spin velocity and spin time

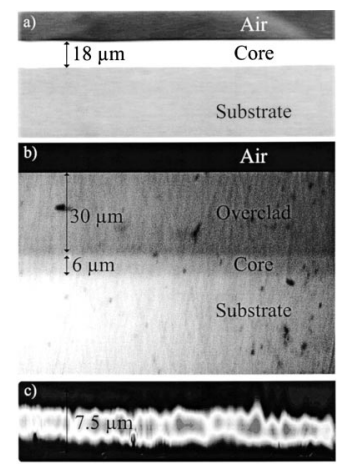

FIG. 3. (a) Micrograph (SEM) showing first deposited layer of core material, (b) overcladding and core layers, and (c) guided mode within core layer.

Downloaded 04 Jul 2006 to 131.227.4.248. Redistribution subject parameters used for the initial core deposition was $4000 \mathrm{rpm}$ for $15 \mathrm{~s}$ and the overcladding layer was $3500 \mathrm{rpm}$ for $10 \mathrm{~s}$. The overcladding surface uniformity was measured to be better than $0.5 \mu \mathrm{m}$ across $25 \mathrm{~mm}$ (profiled with a Tencor atomic force microscope). It was observed that spinning at lower velocities yielded thicker films which normally had a larger area of surface uniformity, almost covering the entire disk area. However, if a thinner core film of several microns is desired, an overcladding layer can be spun onto the thick core film. This process of thinning out a thick spun film by spinning an overcladding layer is through remelting and reflowing of the viscous glass, hence reduction of the core layer size to $6 \mu \mathrm{m}$. A planar chip was cut and end-face polished from this spun disk. The propagation loss at $1.064 \mu \mathrm{m}$ for the film shown in Fig. 3(b) was $<0.2 \mathrm{~dB} \mathrm{~cm}^{-1}$ over a $15 \mathrm{~mm}$ path length indicating good transmission and low scattering requirements for many applications. In addition, observation and measurements of the guided laser mode, shown in Fig. 3(c), was performed with a CCD camera, and it was observed that the guided laser output was in fundamental spatial-mode. Experimental mode size $\left(1 / e^{2}\right.$ intensity) was $7.5 \mu \mathrm{m}$ in the vertical direction. This was confirmed with a software mode-solver giving a good theoretical match of $7.7 \mu \mathrm{m}$. The size of the waveguide mode would appear to be larger than the physical dimensions of the waveguide structure indicative of single mode behavior.

In summary, we have demonstrated the fabrication of highly nonlinear buried planar chalcogenide waveguides using a modified version of the conventional spin coating technique. An infrared transmitting Ga:La:S chalcogenide glass was used to produce uniform films. The optimization of thermally and chemically superior chalcogenide glass, quenched in air without oxygenation or devitrification was necessary. Uniform films and waveguides of $\mathrm{Ga}: \mathrm{La}: \mathrm{S}$ glass were measured to be single-mode in operation and had $<0.2 \mathrm{~dB} \mathrm{~cm}^{-1}$ propagation loss, suitable for use in highly nonlinear integrated optics requiring ultrafast all-optical switching and the generation of supercontinuum.

This work was supported by EPSRC Grant No. GR/ R941 21/01.

${ }^{1}$ G. Lenz, J. Zimmermann, T. Katsufuji, M. E. Lines, H. Y. Hwang, S. Spalter, R. E. Slusher, S. W. Cheong, J. S. Sanghera, and I. D. Aggarwal, Opt. Lett. 25, 254 (2000).

${ }^{2}$ A. K. Mairaj, A. M. Chardon, D. P. Shepherd, and D. W. Hewak, IEEE J. Sel. Top. Quantum Electron. 8, 1381 (2002).

${ }^{3}$ S. K. Sundaram, B. R. Johnson, M. J. Schweiger, J. E. Martinez, B. J. Riley, L. V. Saraf, N. C. Anheier, Jr., P. J. Allen, and J. F. Schultz, Proc. SPIE 5359, 234 (2004).

${ }^{4}$ S. R. Ovshinsky, J. Non-Cryst. Solids 141, 200 (1992).

${ }^{5}$ S. Spalter, H. Y. Wang, J. Zimmermann, G. Lenz, T. Katsufuji, S. W. Cheong, and R. E. Slusher, Opt. Lett. 27, 363 (2002).

${ }^{6}$ G. C. Chern and I. Lauks, J. Appl. Phys. 53, 6979 (1982).

${ }^{7}$ X. Jian and R. M. Almeida, Mater. Sci. Semicond. Process. 3, 339 (2000).

${ }^{8}$ C. C. Huang, D. W. Hewak, and J. V. Badding, Opt. Express 12, 2501 (2004).

${ }^{9}$ D. S. Gill, R. W. Eason, C. Zaldo, H. N. Rutt, and N. A. Vainos, J. Non-Cryst. Solids 191, 321 (1995).

${ }^{10}$ L. B. Shaw, B. Cole, P. A. Thielen, J. S. Sanghera, and I. D. Aggarwal, IEEE J. Quantum Electron. 37, 1127 (2001).

${ }^{11}$ I. Kang, T. D. Krauss, F. W. Wise, B. G. Aitken, and N. F. Borelli, J. Opt. Soc. Am. B 12, 2053 (1995).

${ }^{12}$ D. W. Harwood, E. R. Taylor, Y. Rubin, and G. Deflandre, Glass Technology Proceedings of XIX International Congress on Glass, 2002, Vol. 43, pp. $170-173$.

${ }^{13}$ A. K. Mairaj, R. J. Curry, and D. W. Hewak, Electron. Lett. 40, 421 (2004).

${ }^{14}$ A. G. Emslie, F. T. Bonner, and L. G. Peck, J. Appl. Phys. 29, 858 (1958).
AIP license or copyright, see http://apl.aip.org/apl/copyright.jsp 